\title{
Economics, Psychology, and Social Dynamics of Consumer Bidding in Auctions*
}

\author{
AMAR CHEEMA $^{\dagger}$ \\ PETER T. L. POPKOWSKI LESZCZYC \\ University of Alberta \\ RAJESH BAGCHI \\ University of Colorado at Boulder \\ RICHARD P. BAGOZZI \\ University of Michigan \\ JAMES C. COX \\ University of Arizona \\ UTPAL M. DHOLAKIA \\ Rice University \\ ERIC A. GREENLEAF \\ New York University \\ AMIT PAZGAL \\ Washington University in Saint Louis \\ MICHAEL H. ROTHKOPF \\ Rutgers University \\ MICHAEL SHEN \\ University of Alberta \\ SHYAM SUNDER \\ Yale University \\ ROBERT ZEITHAMMER \\ University of Chicago
}

cheema@wustl.edu

Olin School of Business, CB 1133, Washington University in St. Louis, St. Louis, MO 63130

\section{Abstract}

With increasing numbers of consumers in auction marketplaces, we highlight some recent approaches that bring additional economic, social, and psychological factors to bear on existing economic theory to better understand

*This paper is based on the special session at the 6th Triennial Invitational Choice Symposium, University of Colorado Boulder, June 2004 (co-chaired by the first two authors).

${ }^{\dagger}$ Corresponding author. 
and explain consumers' behavior in auctions. We also highlight specific research streams that could contribute towards enriching existing economic models of bidding behavior in emerging market mechanisms.

Keywords: auctions, bidding, economic psychology, social dynamics, experimental economics

The past decade has seen the advent and growth of online auction marketplaces, with online auction revenues expected to reach $\$ 36$ billion by the year 2007 (C2C and B2C, (Laudon and Traver, 2004, p. 784). Study of specific auction formats for the past several decades has produced rich normative economic theories of rational buyers' and sellers' behavior (see Klemperer, 1999 for a review). A majority of these theories are developed for rational individuals who bid on behalf of firms for resources such as offshore oil leases, or on behalf of wealthy bidders for expensive pieces of art, in auctions with a specific set of rules.

However, tests of normative theories have found that bidders depart from these predictions (see Chakravarti et al., 2002 for a review), highlighting the necessity of studies analyzing the gaps between the behavioral reality and "the well informed, rational, utility maximizing homo economicus of theoretical economics and game theory" (Rothkopf, 1991, p. 40), prompting calls for theoretical and empirical research from an economic as well as a behavioral perspective (Rothkopf and Harstad, 1994).

In addition, most items now being sold in auctions are mass-produced and/or relatively inexpensive, and participants who bid on these products in auctions may receive utility from factors other than the price. Biases arising in these contexts are liable to be less costly than when bidding on one-of-a-kind, big-ticket items such as oil leases or Impressionist paintings. Thus, few of the assumptions required for the theory to be applicable exist in these auction marketplaces. Consequently, researchers need to focus on consumer characteristics and auction mechanisms that affect behavior in these choice contexts.

We focus on a set of economic, psychological, and social factors that are typically not considered in the context of auction behavior, but that improve our understanding of bidders' behavior. We present ongoing research on these factors, and suggest topics for future research.

\section{Auction Marketplaces}

Auction marketplaces with a large number of buyers and sellers of substitutable products bring new challenges for both buyers and sellers. Sellers must determine better ways to auction multiple products over time. Buyers must also decide on a good bidding strategy when faced with a large number of nearly identical items (or close substitutes) in auctions that may end simultaneously, sequentially (one ends and the next starts), or overlap (some end before others).

For consumers who need one unit of a product, facing multiple auctions raises the issue of a budget constraint that may prevent them from bidding in multiple auctions, and/or the possibility of winning multiple auctions if they do bid in more than one auction simultaneously. Suppliers who bid on contracts in overlapping auctions face a similar problem, 
being limited by their capacity to fulfill multiple orders if several bids are accepted. Sellers of multiple products face a different problem when selling products with varying levels of substitutability - should they combine these products and auction the bundle, or should they auction them separately?

\subsection{Overlapping Auctions}

Buyers In September 2004, eBay listed 10,599 auctions for digital cameras lasting up to 10 days (2,572 ending within 24 hours) - a staggering, albeit typical, number of options. Bidders considering hundreds of overlapping auctions may cope by considering only a subset of the available auctions as well as expected future auctions, and satisfice (Simon, 1955). Contextual factors affecting the composition of such a subset are also of theoretical interest.

Zeithammer (2005a) models certain eBay product categories (MP3 players and DVDs) as a set of sequential auctions for identical units (ordered by the ending time), where buyers are informed about specific units coming up for sale in the near future and are assumed to have single-unit demand, and independent private values (IPV). He argues that optimal bidding reduces to solving the tradeoff between winning the auction ending first and the option value of participating in the future auctions, the latter depending on the information about future items. Bidders take detailed information about multiple auctions into account when constructing bids, and bid lower in the current auction when they know about future item availability. Zeithammer (2005b) finds analytically that the sellers are able to regulate buyer bid-shading whenever seller profits are relatively low, and that bid-shading vanishes when the seller profits are near zero.

A related topic of interest is how affiliated values affect prices in overlapping or sequential auctions. Prices could drift upwards because price announcements at the end of an auction may increase bidder valuations in subsequent auctions. Prior experiments (Kagel et al., 1987) suggest that revealing the distribution mean (from which affiliated values are drawn) results in higher bids, although the resulting price increase was found to be not significant.

In contrast, Ashenfelter (1989) reports empirical evidence of decreasing prices in sequential auctions for a single seller of art and wine (see Gale and Hausch, 1994 for a list of possible reasons). Milgrom and Weber (2000) show analytically that in a sequential auction with IPV bidders, while each auction decreases the pool of bidders (the winner leaves), remaining bidders bid higher in the next auction, thus keeping revenue unchanged.

Zeng et al. (forthcoming) study the coordination of purchasing and bidding activities across online auctions and posted offer sites for products with demand complementarities. Such complementarities create interdependencies among purchasing decisions across distinct markets. Of the theoretical models developed, one set focuses on optimal purchasing decisions across several posted offer sites with flat shipping costs, using discrete location theory to solve for optimal purchasing decisions. Another set of models 
focuses on optimal coordination and bidding across simultaneous auctions of complementary items.

Suppliers Pazgal and Iyer (2004) study how capacity constraints affect bids when two projects of different (but known) values $\left(v_{1}>v_{2}\right)$ are offered in a first-price sealed-bid auction, and each of $n$ suppliers (with IPV) can bid on only one of the two projects. They demonstrate empirically that: (a) lower bound of the bids is lower for the higher-valued project (project 1 , with value $v_{1}$ ), (b) willingness to bid on project 1 increases as the ratio $\left(v_{1} / v_{2}\right)$ increases, and (c) bid amount decreases as $n$ increases, leading to more even probabilities of bidding on each project.

Thus, with a large number of participants, bidders are willing to take "long shots" by submitting low bids on the high value project. This has implications for consumer bidding in online auctions as well: if it is costly for bidders to participate in auctions, they may be less likely to bid and/or bid lower when a large number of bidders are participating in the auction.

These studies emphasize the complexity of the decisions faced by bidders in overlapping auctions for substitutable or complementary products. Sellers of multiple products face another decision: whether to offer the products as a bundle, or separately (and, if so, in what order).

\subsection{Product Bundles}

Bundling has traditionally been used as a price discrimination device to separate customers with differing reservation prices (Adams and Yellen, 1976), allowing high markups to be charged to buyers who may be interested in only one of the two bundled products (Schmalensee, 1984). From a buyer's perspective, the auction of a bundle may attract fewer bidders and thus lead to lower prices. From a seller's perspective, an auction of a bundle reduces transaction cost (listing and conducting separate auctions for component products).

However, economic theory predicts that, for more than two bidders, separate auctions of independent component products will yield greater revenue for the seller than an auction of the bundle (Chakraborty, 1999; Palfrey, 1983). Hence, is it ever optimal for the seller to sell a bundle?

Popkowski Leszczyc et al. (2004) study empirically different bundling formats in open ascending-bid (English) auctions to determine the role of component product complementarities on seller revenue. They find that with low product complementarities, separate product component auctions raise more revenue than a single auction of the bundle. However, when complementarity is high, a single auction of the bundle leads to substantially greater seller revenue than do separate component product auctions. Bundling also tends to be more profitable with fewer (versus more) bidders. Participants bid lower in component auctions versus the bundle auction, perhaps because the former carry greater exposure risk (i.e., failing to obtain one of the complementary products).

Popkowski Leszczyc et al. (2004) study experimentally whether consumers use the assessed value of certain-value items to draw inferences about the value of uncertain-value 
items in a bundle of items with low complementarities. Results suggest that a bundle of an item of low but certain value and an item of high and certain value is valued less than the uncertain item alone. However, a bundle of an item of high and certain value with an item of low but uncertain value is valued higher than the summed values of the two items. Informing bidders about the uncertain-value item's value attenuates the effect. This complementarity is also relevant for sequential auctions. Losing the first auction for a product complement may lead bidders to value the subsequent component less. However, winning the auction may raise the value of the complement, and elicit higher bids in the subsequent auction.

\section{Economic Factors}

Models of bidding could be further enriched by incorporating economic factors that impact a bidder's behavior in current marketplaces, such as transaction costs and the parsimonious representations of risk preference, that are generally ignored by game theorists.

\subsection{Transaction Costs}

The time and effort expended by bidders in gathering information, preparing their bids, and in participating in the auction can impose a real and important transaction cost on participation. In general, one may expect transaction costs to lower participation and, hence, seller revenue. However, this is not necessarily true. Lucking-Reiley (1999) found that internet-based Dutch auctions for collectibles produced higher revenue than (strategically equivalent) first-price sealed-bid auctions.

Carare and Rothkopf (2005) attribute these results, in part, to the slow process of online Dutch auctions where bidders incur incremental transaction costs if they delay bidding. The authors develop a game-theoretic model of a slow Dutch auction and derive two symmetric, payoff-equivalent equilibria of the game in the absence of a cost of return (for the bidder to wait and/or return to bid at a lower price) and then consider the more general case of costly return.

They find that, within an appropriate range for the cost of return, seller's revenue increases as a function of that cost. Such costs may apply to Filene's Basement (Bell and Starr, 1993), which marks down prices by a schedule, and could be considered a slow Dutch auction.

\subsection{Risk Preferences}

Violations of revenue equivalence in laboratory auctions are often attributed to bidders' risk aversion (see Chakravarti et al., 2002 for a discussion). Friedman and Sunder (2004) question the benefits of using risk-aversion to explain behavior. They note that even complex functions with many free parameters do a poor job of predicting behavior in out-of-sample data, new tasks, and new contexts. The authors suggest that placing the explanatory burden on potentially observable opportunity sets offers a more robust approach to understanding 
behavior. Analysis of net payoff opportunities, including embedded options and other interactions with existing obligations, permits analysis of risky choice using expected value, i.e., a linear utility function.

A significant amount of work has focused on the effect of risk preferences on bidding. However, it has been difficult to give bidders a risk "score" on the basis of a priori tests that did not include bidding. Using a linear utility function and risk-neutral bidders may yet require other variables to be introduced in the model to explain observed departures from rationality. Thus, it remains an area of interest for researchers to characterize risk preferences parsimoniously.

\section{Social Factors}

Consumers' motives to attend auctions and interact with other bidders and sellers vary widely. Studying these motives and the process of interaction increases our understanding of bidder behavior, and may affect optimal auction design. Also, most business-to-business auction bids are handled by groups and not by individuals. It therefore also behooves auction researchers to study how the decision making of these groups differs from individuals' decisions.

\subsection{Reasons for Participating in Auctions}

While bidders may have several differing motives to attend an auction, little formal attention has been given to categorizing these motives, and to studying their effect on bidding.

For instance, Smith (1993) suggests that buyers may participate in auctions to be a part of the "show," and to communally decide the value of the product. Sellers may use auctions to arrive at a socially determined "fair" price for a product, even if this price is lower than what they could get by private contract (one-on-one). Herschlag and Zwick (2000) also suggest several motivations for online auction participation, including addiction to excitement, competing against rivals for a good deal, and a need for friendship and community.

Greenleaf (2004a) provides a typology of the different reasons that could motivate a buyer to attend an auction. Some of the "rational" reasons include: getting good bargains and paying prices lower than those at fixed price retailers, paying a "fair" market-determined price, and obtaining information about prices. Sellers, on the other hand, may use auctions to reach new customers, save time as compared to individual negotiations, and to sell excess inventory.

Given the social setting of most auctions, consumers may also participate in or attend auctions to gain prestige, to signal membership in a community of specific collectors, hobbyists, or businesspeople (Smith, 1989), to observe people's fall from wealth and signal one's own rise by buying parts of a dispersed estate (Wall, 1997), to satisfy their ego by paying a high price for a product, or simply to seek entertainment from watching other people win and lose.

However, not all of these motives will be equally applicable to auction participation online and in the bricks-and-mortar (BM) world. For instance, bidders who participate for 
social prestige may be more willing to bid high because of social considerations (such as who is bidding, or who is watching) in a BM context. These motives also affect how bidders feel about winning/losing (Section 4). In addition, when bids are determined by groups, social dynamics also need to be considered, along with individuals' motives.

\subsection{Group Bidding}

Groups often decide bids for offshore oil leases, large construction contracts, or expensive collectibles (Smith, 1989), as individuals in the group may possess information that may be important for the overall decision, and/or groups may be less prone to irrational behavior than individual decision-makers. While social psychological research has studied individual and group decisions in non-strategic settings (see Davis, 1992, for a review), there is little work on decision-making of small groups as agents in markets and other strategic games.

Cox and Hayne (2004) compare group and individual decision-making in the context of bidding in common value auctions to determine whether groups make better decisions in market environments characterized by risky outcomes and, if they do, whether this reflects an advantage from having more information available. They vary the distinct information possessed by individual group members as an experimental treatment (by manipulating signals received by the bidders), and use a quantitative measure of deviation from minimallyrational decisions.

The results indicate that when groups are characterized as decision-making entities consisting of more than one individual with distinct information, groups with signal sample size of 5 (i.e., each of the 5 group members receives a value signal drawn from a distribution) were less rational than individuals with signal sample size of 1 .

On the other hand, giving individuals within the groups the same information changes the results. Groups with signal sample size of 1 (i.e., each group member receives the same signal) bid no differently from individuals with signal sample size of 1 . Also, more information about the value of the item caused both individuals and groups to deviate further from rational bidding and this "curse of information" was worse for groups than for individuals.

Cox and Hayne (2005) explore whether incentive differences for individuals in groups affect performance. They set up "nominal groups" where each member submits an individual bids, and these bids are averaged to arrive at the group bid. The payoff is manipulated such that in one experimental treatment all group members shared the payoff equally (cooperative incentive) while in the other treatment the payoffs are shared on the basis of individual group members' bids. The latter creates a "free-riding incentive" as group members who bid the lowest earned the most. Groups with a free-riding incentive are more rational, and bid lower, than cooperative groups or "natural groups" with either small or large signal sample sizes.

Thus, social dynamics within groups, and between buyers and sellers, will often affect bidders' entry decisions, bid, and selling prices. In addition to the social components, some of the motives for individual participation (Section 3.1) are also emotional or goal-driven, affecting bidder behavior from a psychological perspective. We now illustrate how some 
of these psychological factors can affect bidding during the auction and emotions after the auction.

\section{Psychological Factors}

Bidders often do not have a good estimate of an item's value, constructing it when required (Fischhoff, 1991). This value is susceptible to information acquired prior to and during the auction (Cheema et al., 2005a; Häubl and Popkowski Leszczyc, 2003; Kamins et al., 2004).

\subsection{Value Construction and Reference Points}

Dholakia and Simonson (2005) study how making certain reference points explicit affects bidding. As comparative loss aversion is more pronounced when comparisons are explicit (suggested by the seller) rather than implicit (i.e., spontaneously used by consumers; Brenner et al., 1999), the former should induce more cautious bidding. Explicit comparisons could also trigger more cautious evaluation of the information and, contingent on the buyers' interpretation of the seller's intention, an error-prevention orientation (Friestad and Wright, 1994).

Results from an online auction field experiment supported this claim. Explicit comparisons diminished the influence of adjacent auction listings on the winning bid in the focal auction, and led participants to submit lower and later bids. A choice experiment had similar results: explicit instructions to compare option sets increased choice of the compromise option.

In addition to price information, bidders may be affected by external factors such as other bidders' behavior, copying it, and/or changing their value for the item (e.g., Banerjee, 1992; Bikhchandani et al., 1992; Dholakia et al., 2002). Internal factors such as bidder participation motives (Section 3.1) will also affect bidding, and bidder emotions, during the auction process.

\subsection{Multiple Stages of Decision Making}

Bagozzi et al. (1998) suggest that the reasons to enter, bid, or leave auctions emanate from cognitive, emotional, and social processes (see also Ariely and Simonson, 2003). Bagozzi et al. (2003) suggest a decision-making model which could also be applied to an auction setting.

Consider a bidder who enters the auction with a competitive goal of winning the auction. This bidder imagines both goal failure and goal success scenarios, thus experiencing both negative as well as positive anticipated emotions. In the goal failure scenario, commonly anticipated emotions would include disappointment, annoyance, regret, stupidity, guilt, and anger. In contrast, the goal success scenario would entail experiencing relief, satisfaction, happiness, and pride. This bidder would then make a decision about the amount of effort he is willing to expend to pursue his goals contingent on these anticipated emotions. 
Bagozzi (1992) argues that desires are necessary to convert reasons for actions into intentions to act. While goal intention refers to a self-commitment to realize a desired end state, an implementation intention refers to a self-commitment to perform a particular action. In the implementation stage, the bidder activates instrumental behaviors to achieve his goal (bids high). Implementation intentions thus mediate effects of goal intentions on action. In addition, goal outcomes (winning/losing) affect emotions, as discussed in greater detail in Section 4.3.

A decision model could thus be used to study the how goals affect bidder intentions, behavior, and emotions in auctions. Some auction models have included these factors. Sinha and Greenleaf (2000) show that bidding aggressiveness, i.e., bidder desire to win an auction (not just make a profit) can make the seller's reserve price dependent on the number of bidders.

Roth and Ockenfels (2002) demonstrate how bidders' reluctance to bid until the last minute in auctions with timed endings (termed sniping) leads to lower auction prices compared to auctions with "soft" endings. Engelbrecht-Wiggans (1989) demonstrates analytically that bidders in sealed-bid auctions will decrease [increase] bids when they anticipate regret from winning and overpaying [losing]. And Greenleaf (2004b) finds empirical support that anticipated regret by sellers of the possibility that the highest bid will exceed the seller's valuation but not the reserve leads them to lower reserves.

\subsection{Experienced Regret in Auctions}

Cheema et al. (2005b) study empirically how bidders' goals interact with auction characteristics to affect their post-auction regret, contingent on the win/loss outcome. Bidders primed with either a winning focus, or a prudent, value focus participated in either open ascending auctions with irrevocable exit ("Japanese variant" of the English auction) or open descending (Dutch) auctions against simulated bidders (see Cheema et al., 2005a for details).

The deliberative nature of the ascending auction (bidding at each step) led to less regret overall in them than in descending auctions. In ascending auctions, losing bidders reported higher regret than winners, irrespective of the winning/value focus. In descending auctions, too, among winning focused bidders, losing (versus winning) bidders reported higher regret. However, among value-focused bidders, those who won (being the highest and only bidder) feared that they paid too much. This apprehension was greater among bidders who were relatively less certain of the price of the auctioned product.

Losing bidders' regret increased as a function of the lost potential surplus (value - winning bid), both for ascending and descending auctions. In descending auctions, winning focused bidders who lost were more likely to win a subsequent auction for an unrelated product. This result has significant implications for sequential auctions for unrelated products. However, effects of prior auction outcomes on subsequent auctions of related products would be further moderated by product characteristics: winning (versus losing) the first product may make bidders bid higher for subsequent complementary products, but lower for substitutable products. 


\section{Conclusion: The Relevance of Auctions to Marketing}

\subsection{Evolving Marketplaces}

The everyday consumer's participation in this environment creates a need to enrich existing models from an economic as well as behavioral perspective. Researchers also need to identify bidding and selling strategies for new mechanisms in environments such as eBay and other auction sites.

Differences between various selling mechanisms are becoming increasingly blurred as new hybrids emerge. Most online consumer auction sites provide a "Buy it Now" price, a fixed-price alternative for buyers. In addition to giving risk-averse bidders an option to purchase the product without risking paying more in the auction (Budish and Takeyama, 2001) and a profitable accommodation for buyers with strong time preferences (Carare and Rothkopf, 2005) these prices provide buyers a reference point that affects their value for the item (Section 4.1). Other hybrids include similarities between auctions and formal negotiations (Bulow and Klemperer, 1996), and elicitation of "best offers" alongside posted prices.

\subsection{Methodological Tool}

With their fixed structure of interaction, auctions provide a controlled context in which to study decision making under uncertainty (McAfee and McMillan 1996). Researchers can study how consumers process information and change their bidding strategy as the auction progresses and information is revealed (Section 4). This market can also be used to study group decision making dynamics and the effect of incentives on decisions under risk (Section 3.2). Auctions with proper incentives can elicit consumers' value for new products (Hoffman et al., 1993).

\subsection{Conclusion}

We highlight research approaches that focus on additional economic, social, and psychological factors affecting consumers' behavior in auctions, and outline areas for further investigation. These factors could enrich existing economic auction models and help us better understand behavior in emerging market mechanisms.

\section{Acknowledgment}

The authors thank the editor and anonymous reviewers for insightful suggestions and comments.

\section{References}

\footnotetext{
Adams, William, J. and Janet L. Yellen. (1976). “Commodity Bundling and the Burden of the Monopoly,” Quarterly Journal of Economics 90(August), 475-498.
} 
Ariely, Dan and Itamar Simonson. (2003). "Buying, Bidding, Playing or Competing? Value Assessment and Decision Dynamics in Online Auctions," Journal of Consumer Psychology 13(2), 113-123.

Ashenfelter, Orley. (1989). "How Auctions Work for Wine and Art," Journal of Economic Perspectives 3(3), 23-36.

Bagozzi, Richard P. (1992). “The Self-Regulation of Attitudes, Intentions, and Behavior,” Social Psychology Quarterly 55, 178-204.

Bagozzi, Richard P., H. Baumgartner, and R. Pieters. (1998). "Goal-Directed Emotions," Cognition and Emotion 12, 1-26.

Bagozzi, Richard P., Utpal M. Dholakia, and S. Basuroy. (2003). "How Effortful Decisions Get Enacted: The Motivating Role of Decision Processes, Desires, and Anticipated Emotions," Journal of Behavioral Decision Making 16, 273-295.

Banerjee, Abhijit V. (1992). “A Simple Model of Herd Behavior,” Quarterly Journal of Economics 107(3), 797817.

Bell, David E. and Dinny Starr. (1993). Filene’s Basement. Harvard Business School case \#9-594-018.

Bikhchandani, Sushil, David Hirshleifer, and Ivo Welch. (1992). "A Theory of Fads, Fashion, Custom and Cultural Change as Informational Cascades,” Journal of Political Economy 100(5), 992-1026.

Brenner, Lyle, Yuval Rottenstreich, and Sanjay Sood. (1999). "Comparison, Grouping, and Preference," Psychological Science 10(3), 225-229.

Budish, Eric B. and Lis N. Takeyama. (2001). "Buy Prices in Online Auctions: Irrationality on the Internet?" Economics Letters 72(3), 325-333.

Bulow, Jeremy and Paul Klemperer. (1996). “Auctions versus Negotiations,” American Economic Review 86(1), 180-194.

Carare, Octavian and Michael H. Rothkopf. (2005). "Slow Dutch Auctions," Management Science 51(3), $365-373$. Chakravarti, Dipankar, Eric Greenleaf, Atanu Sinha, Amar Cheema, James C. Cox, Daniel Friedman, Teck H. Ho, R. Mark Isaac, Andrew A. Mitchell, Amnon Rapport, Michael H. Rothkopf, Joydeep Srivastava, and Rami Zwick. (2002). "Auctions: Research Opportunities in Marketing," Marketing Letters 13(3), 281-296.

Chakraborty, Indranil. (1999). "Bundling Decisions for Selling Multiple Objects," Economic Theory 13(3), 723 733.

Cheema, Amar, Dipankar Chakravarti, and Atanu Sinha. (2005a). "Drivers of Value Construction and Bidding Behavior in Descending and Ascending Auctions," Working paper, Washington University in St. Louis.

Cheema, Amar, Dipankar Chakravarti, and Atanu Sinha. (2005b). "Outcome-contingent Regret in Descending and Ascending Auctions," Working paper, Washington University in St. Louis.

Cox, James C. and Stephen C. Hayne. (2004). "Barking Up the Right Tree: Are Small Groups Rational Agents?" working paper, University of Arizona.

Cox, James C. and Stephen C. Hayne. (forthcoming). "When Does an Incentive for Free-riding Promote Rational Bidding?” In R. Zwick and A. Rapoport (eds.), Experimental Business Research, vol. II. Springer.

Davis, J. H. (1992). "Some Compelling Intuitions about Group Consensus Decisions: Theoretical and Empirical Research, and Interpersonal Aggregation Phenomena: Selected Examples, 1950-1990," Organizational Behavior and Human Decision Processes 52, 3-38.

Dholakia, Utpal M., Suman Basuroy, and Kerry Soltysinski. (2002). "Auction or Agent (or Both)? A Study of Moderators of the Herding Bias in Digital Auctions," International Journal of Research in Marketing 19, 115-130.

Dholakia, Utpal M. and Itamar Simonson. (2005). "The Effect of Explicit Reference Points on Consumer Choice and Online Bidding Behavior," Marketing Science 24(2), 206-217.

Engelbrecht-Wiggans, Richard. (1989). "The Effect of Regret on Optimal Bidding in Auctions," Management Science 35(6), 685-692.

Fischhoff, Baruch. (1991). "Value Elicitation: Is There Anything in There?" American Psychologist 46, 835-847.

Friedman, Daniel and Shyam Sunder. (2004). "Risky Curves: From Unobservable Utility to Observable Opportunity Sets," working paper, Yale University, New Haven CT.

Friestad, Marian and Peter Wright. (1994). "The Persuasion Knowledge Model: How People Cope with Persuasion Attempts," Journal of Consumer Research 21(June), 1-31. 
Gale, Ian L. and Hausch, Donald B. (1994), "Bottom-fishing and declining prices in sequential auctions," Games and Economic Behavior 7, 318-331.

Greenleaf, Eric A. (2004a). "Why Do People Attend Auctions?" Presentation at the Special Session on Economics, Psychology and Social Dynamics of Consumer Bidding in Auctions, 6th Triennial Invitational Choice Symposium, Estes Park, CO.

Greenleaf, Eric A. (2004b). "Reserves, Regret, and Rejoicing in Open English Auctions," Journal of Consumer Research 31(2), 264-273.

Häubl, Gerald and Peter T. L. Popkowski Leszczyc. (2003). "Minimum Prices and Product Valuations in Auctions," Marketing Science Institute Reports 3(03-117), 115-141.

Herschlag, Miriam and Rami Zwick. (2000). "Internet Auctions: A Popular and Professional Literature Review," Quarterly Journal of Electronic Commerce 1(2), 161-186.

Hoffman, Elizabeth, Dale J. Menkhaus, Dipankar Chakravarti, Ray A. Field, and Glen D. Whipple. (1993). "Using Laboratory Experimental Auctions in Marketing Research: A Case Study of New Packaging for Fresh Beef," Marketing Science 12(3), 318-338.

Kagel, John H., Ronald M. Harstad, and Dan Levin. (1987). "Information Impact and Allocation Rules in Auctions with Affiliated Private Values: A Laboratory Study," Econometrica 55, 1275-1304.

Kamins, Michael, Xavier Dreze, and Valerie S. Folkes. (2004). "Effects of Seller-Supplied Prices on Buyers' Product Evaluations: Reference Prices in an Internet Auction Context," Journal of Consumer Research 30(4), 622-628.

Klemperer, Paul. (1999). “Auction Theory: A Guide to the Literature,” Journal of Economic Surveys 13(3), 227286.

Laudon, Kenneth C. and Carol G. Traver. (2004). E-commerce: Business, Technology, Society, 2nd Ed. Boston, MA: Addison-Wesley.

Lucking-Reiley, David. (1999). "Using Field Experiments to Test Equivalence Between Auction Formats: Magic on the Internet," American Economic Review 89(5), 1063-1079.

McAfee, R. Preston and John McMillan. (1996). "Competition and Game Theory," Journal of Marketing Research 25(August), 263-267.

Milgrom, Paul and Robert J. Weber. (2000). “A Theory of Auctions and Competitive Bidding, II.” In Paul Klemperer (ed.), The Economic Theory of Auctions, Cheltenham: Edward Elgar. vol. 2, pp. 179-194.

Palfrey. Thomas R. (1983). "Bundling Decisions by a Multi-product Monopolist with Incomplete Information," Econometrica 512(March), 463-484.

Pazgal, Amit and Ganesh Iyer. (2004). "(Capacity) Constrained Bidding," working paper, John M. Olin School of Business, Washington University in Saint Louis.

Popkowski Leszczyc, Peter T. L., Gerald Häubl, and Michael Shen. (2004). "An Empirical Analysis of the effectiveness of Bundling Strategies in Auctions," working paper, University of Alberta, CA.

Popkowski Leszczyc, Peter T. L., John W. Pracejus, and Michael Shen. (2005). "Why More Can Be Less: An Inference-Based Explanation for Hyper-Subadditivity in Product Bundles," working paper, University of Alberta, CA.

Roth, Alvin E. and Axel Ockenfels. (2002). "Last Minute Bidding and the Rules for Ending Second-Price Auctions: Evidence from eBay and Amazon Auctions on the Internet," American Economic Review 92(4), 1093-1103.

Rothkopf, Michael H. (1991). "On Auctions with Withdrawable Winning Bids," Marketing Science 10(1), 40-57.

Rothkopf, Michael H. and Ronald M. Harstad. (1994). "Modeling Competitive Bidding: A Critical Essay," Management Science 40(3), 364-384.

Schmalensee, Richard. (1984). "Gaussian Demand and Commodity Bundling," Journal of Business 57(1), 211230.

Simon, Herbert A. (1955). “A Behavioral Model of Rational Choice,” Quarterly Journal of Economics 69, 99-118.

Sinha, Atanu R. and Eric A. Greenleaf. (2000). "The Impact of Discrete Bidding and Bidder Aggressiveness on Seller's Strategies in Open English Auctions: Reserves and Covert Shilling," Marketing Science 19(3), $244-265$. Smith, Charles W. (1989). Auctions: The Social Construction of Value. New York: Free Press.

Smith, Charles W. (1993). "Auctions: From Walras to the Real World.” In Richard Swedberg (ed.), Explorations in Economic Sociology. New York: Sage. 
Wall, Cynthia. (1997). “The English Auction: Narratives of Dismantlings,” Eighteenth Century Studies 1-25. Zeithammer, Robert. (2005a). "Forward-Looking Bidding in Online Auctions," working paper, University of Chicago.

Zeithammer, Robert. (2005b). "An Equilibrium Model of a Dynamic Auction Marketplace,” working paper, University of Chicago.

Zeng, Daniel, James C. Cox and Moshe Dror. (forthcoming). "Coordination of Purchasing and Bidding Activities Across Posted Offer and Auction Markets," Journal of Information Systems and e-Business Management. 